\title{
Communication/Comunicação
}

\section{Epidemiology of extended spectrum $\beta$-lactamase producing Enterobacter bacteremia in a Brazilian hospital}

\author{
Epidemiologia de bacteremia causadas por Enterobacter produtores de $\beta$-lactamases de espectro \\ estendido em um hospital brasileiro
}

\section{Felipe Francisco Tuon ${ }^{1}$,Leila Carolina Bianchet ${ }^{1}$ and Sergio Ricardo Penteado-Filho ${ }^{1}$}

\begin{abstract}
Introduction: Enterobacter can be included in the group of extended spectrum $\beta$-lactamases (EBSL)-producing bacteria, though few studies exist evaluating risk factors associated with this microorganism. A retrospective cohort study was conducted to determine risk factors associated with ESBL-producing-Enterobacter and mortality. Methods: A retrospective cohort study with 58 bacteremia caused by ESBL-producing-Enterobacter ( 28 cases) and non-ESBL ( 30 cases). Results: Risk factors associated with ESBL-Enterobacter were trauma, length of hospitalization, admission to the intensive care unit, urinary catheter and elective surgery $(\mathrm{p}<0.05)$. The survival curves were similar for ESBL and non-ESBL. Conclusions: ESBLproducing-Enterobacter bacteremia is prevalent and the survival curve was similar to non-ESBL-producing strains.
\end{abstract}

Key-words: Extended spectrum $\beta$-lactamases. Enterobacter. Bacteremia.

\section{RESUMO}

Introdução: Enterobacter pode ser incluído no grupo de bactérias produtoras de $\beta$-lactamases de espectro estendido (ESBL), mas existem poucos estudos avaliando fatores de risco para ESBL. Nós realizamos uma coorte retrospective para determiner fatores de risco associados com Enterobacter produtores de ESBL. Métodos: Uma coorte retrospectiva com 58 bacteremias por Enterobacter ESBL ( 28 casos) e não-ESBL (30 casos). Resultados: Fatores de risco para ESBL-Enterobacter foram trauma, tempo de internação, admissão em UTI, sonda vesical e cirurgia eletiva $(p<0.05)$. A mortalidade foi similar entre ESBL e não-ESBL. Conclusões: Enterobacter produtor de ESBL é prevalente e a curva de mortalidade foi semelhante com o grupo não-ESBL.

Palavras-chaves: $\beta$-lactamases de espectro estendido. Enterobacter. Bacteremia.

Infections caused by extended spectrum $\beta$-lactamases (ESBL) producing bacteria has increased mortality in hospitalized patients ${ }^{1}$. Invasive procedures, admission to intensive care units and previous use of antibiotics are the most common risk factors for ESBLproducing bacteria ${ }^{2}$. Enterobacter is a microorganism associated with Amp-C gene resistance that confers resistance to third generation cephalosporins. However, our group has observed a progressive decrease in susceptibility to fourth generation cephalosporin in our institution, suggesting the increase of ESBL-producing strains. Enterobacter can be included in the group of EBSL-producing

1. Division of Infectious and Parasitic Diseases, Hospital Universitário Evangélico de Curitiba, Curitiba, PR, Brazil.

Address to: Dr. Felipe Francisco Tuon. Infectious and Parasitic Diseases Clinic/ Hospital Universitário Evangélico de Curitiba. Al. Augusto Stellfeld 1908/3º andar, SCIH - Bigorrilho, 80730-150 Curitiba, PR, Brasil.

Phone: 5541 3240-5055; Fax: 5541 3240-5274

e-mail: flptuon@gmail.com

Received in 08/12/2009

Accepted in 23/03/2010 bacteria, though few studies exist evaluating risk factors associated with this microorganism.

Even though the treatment of infections caused by ESBL strains is the same for non-ESBL Enterobacter, we believe that certain clinical and/or laboratorial findings or previous antibiotic use could be risk factors for ESBL-producing Enterobacter. Thus, a retrospective cohort study was conducted to determine risk factors associated with ESBL strains of Enterobacter sp.

The retrospective cohort study was conducted at the Hospital Universitario Evangelico de Curitiba. This center is a 660-bed tertiary hospital in Curitiba, a City located in southern Brazil. From January 2006 to January 2009, 884 bacteremia were identified (excluding coagulase negative Staphylococcus) and 58 (6.5\%) were caused by Enterobacter $\mathrm{sp}$. All the patients with bacteremia caused by Enterobacter were included only once using data from the first bacteremia. Only patients older than 12 years of age were evaluated.

Cultures were collected according to the standard protocol used in the hospital and were processed using the BACT/Alert ${ }^{\oplus}$ (bioMerieux, Durham, USA). Enterobacter was identified using biochemical analysis ${ }^{3}$. Susceptibility testing was performed by the disk diffusion method, in accordance with CLSI guidelines, and ESBL was defined using cefepime with amoxicillin/clavulanate disk approximation method ${ }^{4}$.

The following variables were evaluated for each patient: sex; age; previous hospital admission within the preceding 90 days; admission to the intensive care unit; length of hospitalization before bacteremia; use of mechanical ventilation, central venous line, urinary catheter and surgery during the current hospitalization; underlying conditions, such as diabetes mellitus, chronic renal failure, heart failure, cancer; acute renal failure trauma and previous antibiotic use during current hospitalization; previous colonization by Enterobacter. The following laboratorial results were evaluated on the day of diagnosis: hemoglobin, leukocyte, platelet counts, sodium, potassium, creatinine, urea, total billirubin and partial pressure of oxygen from arterial blood.

Thirty-day and in-hospital mortality were registered. Antibiotic treatment was classified as adequate or inadequate. Treatment of each patient was considered adequate if Enterobacter was susceptible to the antibiotic used during bacteremia and treatment was initiated within the first 48 hours of bacteremia diagnosis. For ESBL strains, the only antibiotic considered adequate was carbapenem.

Patients with ESBL-producing Enterobacter bacteremia were compared with patients with non-ESBL bacteremia to determine 
factors associated with resistance. A second analysis was performed comparing patients who died during hospitalization with those who survived. Continuous data were expressed as mean \pm standard deviation (SD) or median with ranges. Frequencies were expressed as percentages. Dichotomous variables were compared using the $\chi^{2}$ test and the MannWhitney test was used for continuous variables. Significance level was set at 0.05 . Odds ratios (OR) with $95 \%$ confidence intervals (95\% CI) were calculated for each variable. Variables in which $95 \%$ CI did not include 1.0 were maintained in the final model.

Kaplan-Meier survival estimates were calculated to evaluate the role of adequate treatment in the outcome of bacteremia caused by ESBL-producing Enterobacter and the difference was assessed using the log-rank test. Significance was determined when $P$ value was lower than 0.05 .

All data were recorded using the software Excel (Microsoft, New York, USA) and the statistical analysis was performed using the software SPSS 11.5 (SPSS, Chicago, USA). Kaplan-Meier survival estimates were determined with GraphPad Prism 4.0 (GraphPad, La Jolla, USA).
A total of 58 patients were included in this study. Twenty-eight (48.2\%) patients were enrolled as ESBL-producing Enterobacter strains and $30(51.8 \%)$ patients were included as non-ESBL. The median age was 52.1 years-old ( 19 to 93 ) and $72.4 \%$ were male. The mean length of hospitalization was 43.9 days $( \pm 71.7)$. The mean duration of hospitalization until first Enterobacter was 20.7 days $( \pm 24.3)$. Patient characteristics and laboratorial data are described in Table 1. The most common species of Enterobacter was E. aerogenes (71\%), followed by E. gergoviae (17\%) and E. cloacae (12\%).

Risk factors associated with ESBL-Enterobacter were trauma, length of hospitalization, admission to the intensive care unit, urinary catheter and elective surgery $(\mathrm{p}<0.05)$.

The 30-day mortality of patients with Enterobacter bloodstream infection was $48.3 \%$. The 30 -day mortality was similar between ESBL and non-ESBL ( $51.7 \%$ vs $46.7 \%$; $=0.29)$. The global mortality showed the same tendency ( $53.4 \%$ vs $46.3, p=0.21)$. In the univariated analysis, urinary catheter, previous use of cefepime, length of hospitalization, admission to the intensive care unit and mechanical ventilation were factors associated with high mortality $(\mathrm{p}<0.05)$.

TABLE 1 - Characteristics of 58 patients with Enterobacter bacteremia.

\begin{tabular}{|c|c|c|c|c|}
\hline Characteristic & $\begin{array}{c}\text { ESBL-Enterobacter } \\
(\mathrm{n}=28)\end{array}$ & $\begin{array}{l}\text { Non-ESBL-Enterobacter } \\
\qquad(\mathrm{n}=30)\end{array}$ & $\begin{array}{c}\text { OR } \\
(95 \% \mathrm{CI})\end{array}$ & $\mathbf{P}$ \\
\hline \multicolumn{5}{|l|}{ Age - yr } \\
\hline mean & $51.8 \pm 20.6$ & $52.4 \pm 15.4$ & $52.1 \pm 17.9$ & 0,89 \\
\hline range & {$[19-93]$} & {$[20-81]$} & {$[19-93]$} & \\
\hline \multicolumn{5}{|l|}{ Gender - n (\%) } \\
\hline male & $19(68.0)$ & $23(77.0)$ & $0.64(0.20-2.05)$ & 0,34 \\
\hline female & $9(32.0)$ & $7(23.0)$ & & \\
\hline \multicolumn{5}{|l|}{ Coexisting diseases - n (\%) } \\
\hline diabetes mellitus & $4(14.0)$ & $6(20.0)$ & $0.67(0.17-2.67)$ & 0.14 \\
\hline chronic renal failure & $2(7.0)$ & $7(23.0)$ & $0.25(0.05-1.34)$ & 0.17 \\
\hline heart failure & $6(21.0)$ & $6(20.0)$ & $1.09(0.31-3.89)$ & 0,31 \\
\hline arterial systemic hypertension & $6(21.0)$ & $12(40.0)$ & $0.41(0.13-1.31)$ & 0,13 \\
\hline neoplastic diseases & $5(18.0)$ & $8(26.0)$ & $0.60(0.17-2.11)$ & 0,44 \\
\hline trauma & $11(26.0)$ & $4(13.0)$ & $4.21(1.15-15.39)$ & $<0.05$ \\
\hline Days before Enterobacter & $24.5 \pm 28.8$ & $17.1 \pm 19.1$ & & 0,25 \\
\hline Duration of hospitalization & $61.2 \pm 81.3$ & $27.7 \pm 23.6$ & & $<0.05$ \\
\hline \multicolumn{5}{|l|}{ Risk factor - n (\%) } \\
\hline intensive care unit & $20(71.0)$ & $13(43.0)$ & $3.27(1.10-9.75)$ & $<0.05$ \\
\hline previous admission ( $<90$ days $)$ & $18(64.0)$ & $17(56.0)$ & $1.38(0.48-3.96)$ & 0,37 \\
\hline mechanical ventilation & $20(71.0)$ & $16(53.0)$ & $2.19(0.74-6.50)$ & 0,12 \\
\hline central venous catheter & $22(78.0)$ & $22(73.0)$ & $1.33(0.40-4.48)$ & 0,43 \\
\hline vesical urinary catheter & $23(82.0)$ & $17(55.0)$ & $3.52(1.05-11.76)$ & $<0.05$ \\
\hline elective surgery & $20(71.0)$ & $14(46.0)$ & $2.86(0.96-8.49)$ & $<0.05$ \\
\hline \multicolumn{5}{|l|}{ Laboratorial findings - mean $\pm \mathrm{SD}$} \\
\hline hemoglobin $(\mathrm{g} / \mathrm{dL})$ & $10.6 \pm 2.0$ & $9.9 \pm 5.4$ & $10.3 \pm 5.4$ & 0,22 \\
\hline leucocytes $\left(1,000 x\right.$ cells $\left./ \mathrm{mm}^{3}\right)$ & $12.1 \pm 8.0$ & $12.1 \pm 9.4$ & $12.1 \pm 8.7$ & 0,98 \\
\hline immature cells (\%) & $18.7 \pm 13.0$ & $19.2 \pm 14.3$ & $18.9 \pm 13.6$ & 0,88 \\
\hline platelets $(1,000 \mathrm{x}$ cells $/ \mathrm{mm} 3)$ & $191.8 \pm 159.2$ & $135.9 \pm 87.8$ & $163.8 \pm 130.1$ & 0,16 \\
\hline creatinine $(\mathrm{mg} / \mathrm{dL})$ & $1.5 \pm 1.6$ & $2.7 \pm 2.2$ & $2.1 \pm 2.7$ & 0,07 \\
\hline partial pressure oxygen $(\mathrm{mmHg})$ & $105.1 \pm 50.2$ & $96.6 \pm 68.1$ & $101.3 \pm 58.3$ & 0,11 \\
\hline billirubin (mg/dL) & $1.52 \pm 1.6$ & $3.6 \pm .5 .7$ & $1.7 \pm 2.1$ & 0,14 \\
\hline Previous antibiotic use - $n(\%)$ & $9(32.0)$ & $13(43.0)$ & $0.62(0.21-1.81)$ & 0,67 \\
\hline third generation cephalosporin & $3(10.0)$ & $7(23.0)$ & $0.39(0.09-1.71)$ & 0,17 \\
\hline fourth generation cephalosporin & $8(28.0)$ & $3(10.0)$ & $3.60(0.85-15.31)$ & 0,07 \\
\hline carbapenem & $4(14.0)$ & $4(13.0)$ & $1.08(0.24-4.83)$ & 0,6 \\
\hline
\end{tabular}


The antibiotic therapy was incorrect in $93.3 \%$ in the non-survival group and $82 \%$ in the survival group. The inadequate therapy was corrected in $70.7 \%$ of these patients. KaplanMeier survival showed a similar curve of mortality in ESBL and non-ESBL (Figure 1).

Enterobacter is a less important microorganism than other ESBLproducing bacteria (Escherichia coli and Klebsiella pneumoniae) in the medical literature. The origin of Enterobacter infection is related with bacterial translocation from the gastrointestinal tract, the habitat of this pathogen. The incidence of ESBL-strains in

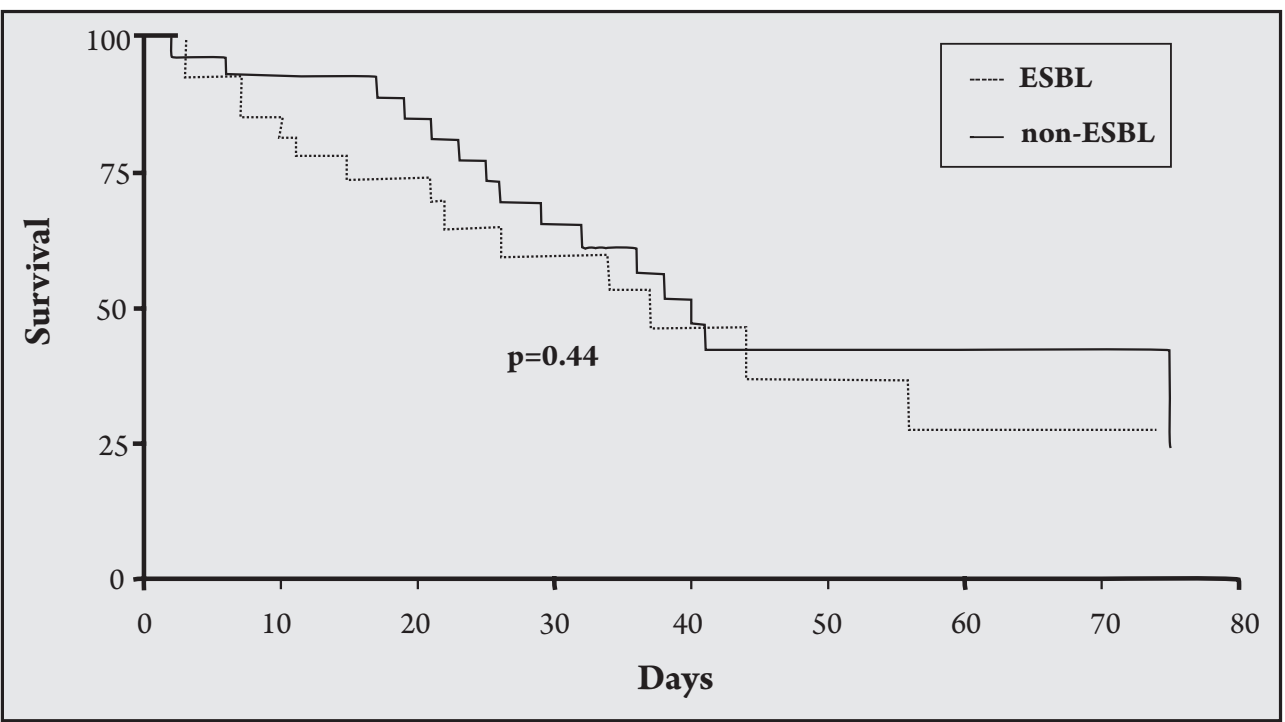

FIGURE 1 - Mortality curve from patients with ESBL-producing Enterobacter bacteremia. our institute is high, achieving $60 \%$ in Klebsiella pneumoniae bacteremia.

Hospitalization time before Enterobacter bacteremia was similar between ESBL and non-ESBL (more than 15 days), suggesting that a prolonged stay in the hospital was not a condition for ESBL Enterobacter. In the univariated analysis, intensive care unit admission, urinary catheter, elective surgery and trauma were risk factors associated with ESBL-strains. All these conditions are related to the severe conditions of the patients, as well as use of large spectrum antibiotics. A published previously study verified irrelevant risk factors for Enterobacter bacteremia among other bacteria, but no comparison was performed regarding different resistance profile ${ }^{5}$. Chang et $\mathrm{al}^{6}$ showed that fourth generation cephalosporin resistance was an independent risk factor of mortality in Enterobacter bacteremia ${ }^{6}$. The mortality curve showed a tendency of higher mortality in the first 15 days after bacteremia caused by ESBL strains, with no statistical significance.

Risk factors for death were similar to those determined for the ESBL-strain, mainly associated with invasive procedures, previous use of cefepime and admission to the intensive care unit.

The mortality of Enterobacter bacteremia is high and most patients in the death group were being administered inadequate therapy. The number of cases in this study does not permit a significant result to confirm this logical tendency. However, this demonstrated that the service needs to change its empirical therapy for patients with bacteremia, especially after 15 days of admission. In another study, $66 \%$ of inadequate empirical therapy had been used until final culture with further adequacy ${ }^{6}$. Most patients were using piperacillin/ tazobactam or cefepime during bacteremia (data not shown) and carbapenem should be used empirically until final cultures, avoiding the up-escalation therapy shown in the present study, where most physicians corrected the therapy following final culture, increasing the spectrum of the antibiotic.

Enterobacter is a frequent pathogen in bacteremia, the mortality is high and ESBL-producing strains are prevalent in our hospital, following the tendency of other Enterobacteriaceae related with this mechanism of resistance, empirical use of carbapenem should be considered in this pattern of hospital, since this study demonstrated that ESBL strains can occur early.

\section{CONFLICT OF INTEREST}

The authors declare that there is no conflict of interest.

\section{REFERENCES}

1 Marra AR, Pereira CA, Castelo A, do CF, Jr., Cal RG, Sader HS, et al. Health and economic outcomes of the detection of Klebsiella pneumoniae-produced extended-spectrum beta-lactamase (ESBL) in a hospital with high prevalence of this infection. Int J Infect Dis 2006;10: 56-60.

2 Paterson DL, Bonomo RA. Extended-spectrum beta-lactamases: a clinical update. Clin Microbiol Rev 2005;18: 657-686.

3 York M. Aerobic Bacteriology. In: Isenberg HI, editor. Clinical Microbiology Procedures Handbook. 2 ed. New York: ASM Press, 2004. p. 3.17.1-3.17.48.

4 Clinical and Laboratory Standard Institute. Performance standards for antimicrobial disk susceptibility testing; Fifteenth Informational Supplement. Wayne: Clinical and Laboratory Standard Institute; 2005.

5 Blot SI, Vandewoude KH, Colardyn FA. Evaluation of outcome in critically ill patients with nosocomial enterobacter bacteremia: results of a matched cohort study. Chest 2003; 123: 1208-1213.

6 Chang EP, Chiang DH, Lin ML, Chen TL, Wang FD, Liu CY. Clinical characteristics and predictors of mortality in patients with Enterobacter aerogenes bacteremia. J Microbiol Immunol Infect 2009; 42: 329-335. 